\title{
An exploratory pilot investigation of neurosteroids and self-reported pain in female Iraq/Afghanistan-era Veterans
}

\author{
Jennifer C. Naylor, PhD; $;^{1-2}$ Jason D. Kilts, PhD; ${ }^{1-2}$ Jennifer L. Strauss, PhD; ${ }^{1-2}$ Steven T. Szabo, MD, PhD; ${ }^{1-2}$ \\ Charlotte E. Dunn, BA; ${ }^{1}$ H. Ryan Wagner, PhD; ${ }^{1-2}$ Robert M. Hamer, PhD; ${ }^{3 \dagger}$ Lawrence J. Shampine, BS; ${ }^{1-2}$ \\ Joseph R. Zanga, MD; ${ }^{4}$ Department of Veterans Affairs Mid-Atlantic Mental Illness Research, Education, and \\ Clinical Center Workgroup; Christine E. Marx, MD $^{1-2^{*}}$ \\ ${ }^{1}$ Research and Development/Mental Health Services, Durham Department of Veterans Affairs Medical Center \\ (VAMC), Durham, NC; and Veterans Integrated Service Network-6 Mid-Atlantic Mental Illness, Research, Education \\ and Clinical Center, Durham VAMC, Durham, NC; ${ }^{2}$ Department of Psychiatry and Behavioral Sciences, Duke Univer- \\ sity Medical Center, Durham, NC; ${ }^{3}$ Departments of Psychiatry and Biostatistics, University of North Carolina, Chapel \\ Hill, NC; ${ }^{4}$ Ambulatory Care Service Line and Mental Health Care Service Line, Durham VAMC, Durham, NC
}

\begin{abstract}
Female Veterans are the most rapidly growing segment of new users of the Veterans Health Administration (VHA), and a significant proportion of female Veterans receiving treatment from VHA primary care providers report persistent pain symptoms. Currently, available data characterizing the neurobiological underpinnings of pain disorders are limited. Preclinical data suggest that neurosteroids may be involved in the modulation of pain symptoms, potentially via actions at gamma-aminobutyric acid (GABA) and N-methyl-D-aspartate (NMDA) receptors. Dehydroepiandrosterone (DHEA) and dehydroepiandrosterone sulfate (DHEAS) are neurosteroids that modulate inhibitory GABA receptors and excitatory NMDA receptors, producing complex neuronal effects. Emerging evidence from male Iraq/Afghanistan-era Veterans suggests that reductions in neurosteroid levels are associated with increased pain symptoms and that neurosteroids may be promising biomarker candidates. The current exploratory study thus examined associations between self-reported pain symptoms in 403 female Iraq/Afghanistan-era Veterans and serum DHEAS and DHEA levels. Serum DHEAS levels were inversely correlated with low back pain in female Veterans (Spearman $r=-0.103 ; p=0.04$ ). Nonparametric analyses indicate that female Veterans reporting moderate/extreme low back pain demonstrated significantly lower DHEAS levels than those reporting no/little low back pain $(|Z|=2.60 ; p=0.009)$. These preliminary findings support a role for DHEAS in pain physiology of low back pain and the rationale for neurosteroid therapeutics in pain analgesia.
\end{abstract}

Key words: Afghanistan, back, biomarker, dehydroepiandrosterone, dehydroepiandrosterone sulfate, DHEA, DHEAS, female, Iraq, low back pain, neurosteroid, novel, pain, therapeutic, Veteran.

\section{INTRODUCTION}

Many Iraq and Afghanistan-era Veterans continue to experience unremitting pain symptoms. Chronic pain disorders are very costly, resulting in significant

Abbreviations: DHEA $=$ dehydroepiandrosterone; DHEAS = dehydroepiandrosterone sulfate; $\mathrm{GABA}_{\mathrm{A}}=$ gamma-aminobutyric acid receptor $\mathrm{A}$; IRB = institutional review board; $\mathrm{MIRECC}=$ Mid-Atlantic Mental Illness Research, Education and Clinical Center; NMDA = N-methyl-D-aspartate; PDMH Study = Study of Post-Deployment Mental Health; SCL = Symptom Checklist; $\mathrm{VA}=$ Department of Veterans Affairs; VHA = Veterans Health Administration.

*Address all correspondence to Christine E. Marx, MD; Durham VA Medical Center, 508 Fulton St, Durham, NC 27705; 919-286-0411, ext 3626. Email: christine.marx@va.gov or christine.marx@duke.edu

http://dx.doi.org/10.1682/JRRD.2014.11.0294

$\dagger$ Deceased. 
disabling effects [1], and health-related disabilities such as chronic pain are a multibillion dollar annual expense for the Veterans Health Administration (VHA) [2]. Additionally, chronic pain disorders can be difficult to manage in Iraq/Afghanistan-era Veterans because this cohort often reports complex co-occurring physical and psychological symptoms [3-5]. Commonly used pharmacological treatments for pain are frequently suboptimal in their efficacy and/or side effect profiles. Opiates, for example, are effective analgesics but demonstrate significant addictive potential, and accidental or intentional misuse can result in dangerous or lethal side effects. New treatment interventions that are both safe and efficacious are thus urgently needed, in addition to the identification of biomarker candidates associated with pain symptoms and the prediction of therapeutic response.

Both preclinical and clinical evidence suggest that there are significant sex differences in pain perception and prevalence. In civilian populations, women tend to have lower pain thresholds, lower pain tolerance, and greater experimentally evoked pain than men [6-8]. Additionally, women report more migraine [9-10] and tension headaches [11], orofacial pain [12-14], fibromyalgia symptoms [15], and musculoskeletal pain [16]. Women also report more severe pain that is longer in duration [17-18] and are more sensitive to temporal summation over time [19]. Sex differences in pain prevalence have also been reported in Veteran populations [20-21], although few studies have addressed these differences in the Iraq/Afghanistan-era cohort [22-23]. Findings from one study in Iraq/Afghanistan-era Veterans showed female Veterans were less likely to report pain overall, but if pain was reported, it was likely to be moderate or severe [22]. And, as noted in a second investigation also using a cohort of Iraq/Afghanistan-era Veterans, while female Veterans were no more likely to report specific pain, the risk of developing joint problems, musculoskeletal pain, and back problems increased 1 to $7 \mathrm{yr}$ following deployment [23]. Because female Veterans are the fastest growing segment of VHA users [24], it is important to examine pain symptoms and their neurobiological correlates in female Veterans specifically.

While sex differences appear to exist in pain perception for both Veterans and non-Veterans, the neurobiological mechanisms contributing to these differences have not yet been completely characterized. Accruing data suggest that neurosteroids, endogenous molecules found both in the brain and in the periphery [25-27], may be involved in the pathophysiology of pain and that neurosteroids may also have therapeutic potential. The majority of analgesia research with neurosteroids has focused predominately on positive modulators of the gamma-aminobutyric acid receptor $\mathrm{A}\left(\mathrm{GABA}_{\mathrm{A}}\right)$, such as allopregnanolone. However, two other neurosteroids, dehydroepiandrosterone (DHEA) and dehydroepiandrosterone sulfate (DHEAS) have also been implicated in the pathophysiology of pain [28-35]. These neurosteroids have complex neuronal effects and are relatively weak N-methyl-D-aspartate (NMDA) and $\mathrm{GABA}_{\mathrm{A}}$ receptor modulators [36-37]. A number of reports suggest that DHEAS levels are associated with pain symptoms, although these effects may differ between males and females. For example, DHEAS levels are inversely correlated with musculoskeletal pain and distress in menopausal women [38], and lower DHEAS levels are associated with increased pain sensitivity in postmenopausal women with fibromyalgia [30]. Conversely, administration of DHEAS in male mice has been shown to produce mechanical allodynia and facilitate pain [35], and there is a modest positive relationship between DHEAS and chest pain in a small sample of 82 male Iraq/Afghanistan-era Veterans [33]. Although the precise roles for DHEAS in pain pathophysiology remain undetermined, DHEAS levels do appear to be relevant to pain symptoms, and may differentially affect males and females.

Levels of DHEA (the unsulfated form of DHEAS) have been generally reported to be inversely associated with pain and to produce possible analgesic effects. For example, low doses of supplemental DHEA have resulted in reduced joint pain in males with partial androgen deficiency [39], and DHEA levels are reduced in the spinal cords of male mice with neuropathic pain-related injuries [32]. In addition, both DHEA [28] and DHEAS [40] levels are reduced in individuals who report pain and who are taking nonsteroidal anti-inflammatory drugs or opiate medications. A number of clinical investigations have also shown that DHEA may have potential as a therapeutic intervention in conditions that are highly co-occurring in patients with pain disorders. For example, reduced levels of DHEA are associated with depression-like symptoms in animal models [41], and reductions in DHEA [42] and DHEAS [43-44] are also associated with depression and anxiety symptoms in clinical populations. Furthermore, two recent functional magnetic resonance imaging studies in healthy adult men suggest that a single dose of DHEA modulates neurocircuitry involved in anxiety and depression [45-46]. In addition, a randomized, double-blind placebo-controlled trial of DHEA resulted 
in improvement for negative symptoms, depression, and anxiety symptoms in patients with schizophrenia [47]an effect that was more pronounced in females than in males. In addition, DHEA administration appears to improve midlife depression symptoms [48]. Together, these findings suggest that DHEA and/or DHEAS levels may have biomarker utility and that administration of these neurosteroids could represent a novel therapeutic intervention for pain and commonly co-occurring disorders.

There are significant sex differences in DHEA and DHEAS levels, and both of these neurosteroids are considerably lower in women than in men of the same age (DHEA and DHEAS markedly decline with age in both sexes). It is thus possible that these sex differences in neurosteroid levels may contribute to differences in the underlying pathophysiology of pain between sexes $[6,7,19]$. Sex differences in pain symptoms and their neurobiological correlates also have ramifications for therapeutic interventions. Several studies suggest that there are sex differences in therapeutic response in both animals and humans [49]. Given the presence of baseline sex differences in neurosteroid levels, it is possible that the development of these molecules as novel therapeutics could be specifically tailored for pain reduction or alleviation in female clinical populations. We thus conducted an exploratory pilot study investigating serum samples from 403 female Iraq/Afghanistan-era Veterans to determine the relationship between self-reported pain symptoms and endogenous levels of DHEA and DHEAS.

\section{METHODS}

\section{Study Population}

The study protocol was approved by the local institutional review boards (IRBs) at the Durham Department of Veterans Affairs (VA) Medical Center, Hampton VA Medical Center, Hunter Holms McGuire VA Medical Center, and W.G. (Bill) Hefner VA Medical Center, and all participants provided written informed consent. Research participants included 403 female Iraq/Afghanistan-era Veterans who were enrolled in the VA MidAtlantic Mental Illness Research, Education and Clinical Center (MIRECC) Study of Post-Deployment Mental Health (PDMH Study) between 2005 and 2012. The PDMH Study consists of one study visit (on rare occasion, Veterans return the following day to complete any remaining study assessments); it is a data and blood repository consisting of (1) self-reported mental and physical health information and (2) serum and other blood samples collected from Iraq/Afghanistan-era Veterans on the same day as the mental and physical health assessments. The only eligibility requirement for participation in the PDMH Study is a history of service in the U.S. military since September 11, 2001 (Iraq/Afghanistan era). To date, the PDMH Study continues to enroll. PDMH Study participants are recruited by approved IRB methods (flyers, letters, telephone calls) and enrolled at one of four participating VA sites.

\section{Blood Draw Procedures}

Blood samples were collected via venipuncture by qualified personnel trained in phlebotomy. Because the PDMH Study is a one-time study visit, blood samples were collected on the same day that study assessments were administered. Approximately 90 percent of the 403 female Veterans in the current study received a blood draw between 10:30 a.m. and 2:30 p.m.

\section{Self-Reported Pain Measure: Symptom Checklist-90-R}

The Symptom Checklist (SCL)-90-R, which is a 90item questionnaire that includes four ratings about pain symptom severity over the past $7 \mathrm{~d}$, was completed by all study participants. The four pain items on the SCL-90-R assess the following symptoms: headache (SCL-1), chest pain (SCL-12), low back pain (SCL-27), and muscle soreness (SCL-42) [50] and comprised our primary outcome measures. There were five possible response options for pain ratings: none (level 0), a little (level 1), moderate (level 2), quite a bit (level 3), and extreme (level 4), and therefore responses were characterized by a five-level integer scale. For nonparametric bivariate Mann-Whitney analyses, pain scores were dichotomized as previously described [33]. Therefore, individuals endorsing pain levels of 0 or 1 on an SCL-90-R pain item were designated to the "low pain" condition (no pain or a little pain), while individuals endorsing pain levels of 2 , 3 , or 4 were designated to the "high pain" condition (moderate to extreme pain).

\section{Neurosteroid Analyses}

Serum DHEAS and DHEA levels were determined using commercially available radioimmunoassay kits (Beckman Coulter; Indianapolis, Indiana) according to manufacturer directions. 


\section{Statistical Analyses}

Possible associations between each of the selected SCL-90-R pain items and serum levels of DHEA and DHEAS were tested using Spearman correlation procedures. Because age and smoking are known to influence DHEA and DHEAS levels, correlations were calculated controlling (partialing) for the latter two factors. In a second series of analyses, differences in neurosteroid levels between dichotomized pain levels were tested using nonparametric Mann-Whitney-Wilcoxon rank procedures. Corrected rates controlling the family-wise error rate were based on the Hochberg step-up procedure [51] and applied to tests involving the four individual SCL-90-R items.

\section{RESULTS}

\section{Study Participants}

Mean age of participants was $36.62 \pm 9.76 \mathrm{yr}$. Of the participants, 29.53 percent identified as Caucasian and 29.18 percent were currently married. Mean years of formal education was $13.86 \pm 3.61 \mathrm{yr}$, and 20.35 percent reported they were currently smoking (Table $\mathbf{1})$.

\section{Symptom Checklist-90-R Pain Items and Serum DHEA and DHEAS}

Median serum DHEAS levels were inversely correlated with self-reported low back pain in female Iraq/ Afghanistan-era Veterans $(r=-0.103 ; p=0.04$, uncorrected for multiple comparisons in this exploratory study). There were no significant DHEAS correlations

Table 1.

Demographic data for analysis cohort of 403 female Iraq/Afghanistanera Veterans.

\begin{tabular}{lrc}
\hline \multicolumn{1}{c}{ Variable } & $\boldsymbol{n}$ & Percent or Mean \pm SD \\
\hline Age $(\mathrm{yr})$ & $403^{*}$ & $36.62 \pm 9.76$ \\
Race $(n)$ & & \\
$\quad$ Caucasian & 119 & 29.53 \\
African American & 260 & 64.52 \\
Native American & 4 & 0.99 \\
Asian & 4 & 0.99 \\
Pacific Islander & 1 & 0.25 \\
Multiracial and Other & 15 & 3.72 \\
Married & 117 & $29.18^{\dagger}$ \\
Education (yr) & $396^{*}$ & $13.86 \pm 3.61$ \\
Current Smoker & 81 & $20.35^{\dagger}$ \\
${ }^{*}$ Data available. & \\
${ }^{\dagger}$ Calculated from available data. & & \\
SD = standard deviation. & & \\
\hline \hline
\end{tabular}

with headache, chest pain, or muscle soreness (nor were there significant correlations with DHEA and any of the four pain items). This finding with serum DHEAS and low back pain was also supported by nonparametric Mann-Whitney analyses, however, which showed that female Veterans reporting moderate to extreme low back pain demonstrated significantly lower median (quartile 1, quartile 3) serum DHEAS levels $(818.87 \mathrm{ng} / \mathrm{mL}$ [525.44, 1,285.33]) compared with female Veterans reporting no low back pain or minimal low back pain $(1,002.42 \mathrm{ng} / \mathrm{mL}$ [683.73, 1,399.21], $|Z|=2.60 ; p=0.009$; adjusted $p=$ 0.04; Table 2). The other three pain items (headache pain, chest pain, and muscle soreness) were not significantly altered between these two groups (nor were median serum DHEA levels different in the high vs low pain groupings for any of the four pain items, Table 3). As anticipated, DHEA and DHEAS levels were significantly inversely correlated with age (DHEA: $r=-0.31$, $p<0.001$; DHEAS: $r=-0.45, p<0.001)$, and both DHEA and DHEAS levels were significantly positively correlated with smoking (DHEA: $r=0.20, p<0.001$; DHEAS: $r=0.15, p<0.002)$.

\section{DISCUSSION}

Results of the current exploratory study show that serum DHEAS levels are inversely correlated with selfreported low back pain in a cohort of 403 female Iraq/ Afghanistan-era Veterans and that female Veterans reporting moderate to severe low back pain have significantly lower serum DHEAS levels than female Veterans reporting no pain or little pain.

It is currently unclear why low back pain is the sole pain symptom significantly associated with decreased serum DHEAS levels in the current study. Although the SCL-90-R does not account for whether pain symptoms are acute or chronic in nature, it is possible that selfreported low back pain in this Veteran cohort is more chronic than self-reported muscle, headache, and chest pain, as the latter pain symptoms may be more intermittent. Thus, it is possible that chronic, rather than acute, pain symptoms are related to changes in serum DHEAS levels. This pilot exploratory biomarker investigation was not designed to interrogate mechanisms of action involving DHEAS that are specific to back pain compared with 
Table 2.

Dehydroepiandrosterone sulfate levels as function of Symptom Checklist-90-R (SCL-90-R) pain items dichotomized into low and high categories.

\begin{tabular}{|c|c|c|c|c|c|c|c|c|}
\hline Symptom & $n$ & Mean \pm SE & $\begin{array}{l}\text { Median } \\
\text { (ng/mL) }\end{array}$ & Q1 & Q3 & $\begin{array}{c}\text { Mann-Whitney- } \\
\text { Wilcoxon }|\mathrm{Z}|\end{array}$ & Probability & $\begin{array}{c}\text { Adjusted } \\
\text { Probability }\end{array}$ \\
\hline \multicolumn{9}{|l|}{ Headache Pain } \\
\hline Low $^{*}$ & 197 & $994.60 \pm 36.79$ & 929.18 & 605.93 & $1,315.64$ & 0.73 & 0.47 & 0.87 \\
\hline \multicolumn{9}{|l|}{ Chest Pain } \\
\hline Low $^{*}$ & 332 & $974.41 \pm 28.22$ & 886.47 & 584.36 & $1,291.89$ & 1.77 & 0.87 & 0.87 \\
\hline $\operatorname{High}^{\dagger}$ & 71 & $1,016.28 \pm 73.25$ & 987.00 & 589.39 & $1,315.64$ & - & - & - \\
\hline Low $^{*}$ & 179 & $1,044.66 \pm 38.53$ & $1,002.42$ & 683.73 & $1,399.21$ & 2.60 & 0.009 & 0.04 \\
\hline $\operatorname{High}^{\dagger}$ & 224 & $931.54 \pm 36.26$ & 818.87 & 525.44 & $1,285.33$ & - & - & - \\
\hline \multicolumn{9}{|l|}{ Muscle Soreness } \\
\hline Low ${ }^{*}$ & 244 & $1,003.29 \pm 34.58$ & 929.99 & 607.09 & $1,294.83$ & -0.83 & 0.41 & 0.87 \\
\hline $\operatorname{High}^{\dagger}$ & 159 & $948.78 \pm 41.42$ & 853.22 & 561.20 & $1,299.23$ & - & - & - \\
\hline $\begin{array}{l}\text { *SCL-90-R pain rat } \\
{ }^{\dagger} \text { SCL-90-R pain rat } \\
\mathrm{Q}=\text { quartile, } \mathrm{SE}=\end{array}$ & $\begin{array}{l}-1 . \\
-4 . \\
\text { rd erro }\end{array}$ & & & & & & & \\
\hline
\end{tabular}

Table 3.

Dehydroepiandrosterone levels as function of Symptom Checklist-90-R (SCL-90-R) pain items dichotomized into low and high categories.

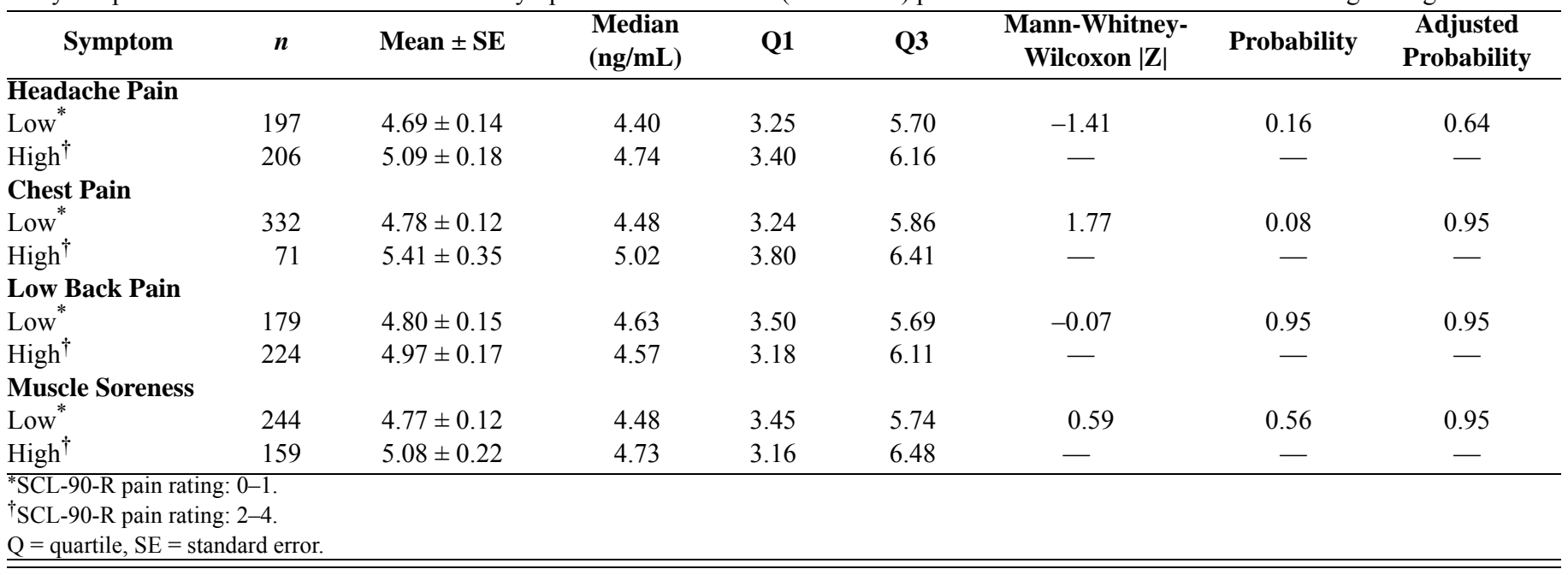

other types of pain, however, and addressing this question would require modeling approaches in rodents that are beyond the scope of the current clinical effort. In addition, these preliminary results would optimally first be replicated in larger clinical cohorts prior to investigating possible neurosteroid mechanisms of action that may be specific to back pain in reverse-translation efforts utilizing clinical findings to inform mechanistically directed rodent studies. Given that only one small correlation between low back pain symptoms and DHEAS levels was significant, the finding could also be a spurious one. Nonetheless, these findings contribute additional evidence to a growing body of scientific literature suggesting that neurosteroids may play an important role in the pathophysiology of pain analgesia and may have promise for pain therapeutics.

\section{Neurosteroids as Biomarker Candidates for Pain}

These findings provide additional support for the quantification of serum DHEAS levels as possible biomarker candidates for pain conditions. Identification of biomarkers associated with pain symptoms could help detect risk factors for the development of pain symptoms and guide the development of novel neurosteroid therapeutics for pain 
disorders. Based on these current findings and prior reports $[30,38,40,48]$, DHEA administration could have therapeutic utility considering it markedly increases DHEAS levels [45-46,48], and quantifying these neurosteroids may have biomarker potential. For example, although the associations found in this study cannot elucidate causation, it is possible that individuals with low DHEAS levels at baseline may be more vulnerable to the development of chronic pain - and that pain symptoms could be ameliorated by restoring DHEAS and/or enhancing DHEAS levels through exogenous administration of DHEA or other neurosteroids. Conversely, it is also possible that pain itself contributes to decreases in DHEAS.

\section{DHEA and DHEAS: Postulated Mechanisms of Action in Pain}

The inverse association of DHEAS with low back pain is consistent with accruing data demonstrating potential analgesic properties of DHEAS, suggesting that the modulation of DHEAS or other endogenous neurosteroids may hold promise for therapeutic intervention in pain disorders. However, the underlying mechanism(s) remain unclear and are likely multifaceted. Although the current study was not designed to investigate possible neurosteroid mechanisms of action in the neurobiology of pain regulation, several possibilities from prior preclinical studies merit mention. For example, DHEA and DHEAS modulate actions of inhibitory $\mathrm{GABA}_{\mathrm{A}}$ and excitatory NMDA receptors. These neurosteroids are weak negative modulators of $\mathrm{GABA}_{\mathrm{A}}$ and positive modulators of NMDA receptors [36-37], and thus their receptor activity profiles are not necessarily consistent with pain analgesia (i.e., many analgesics are positive modulators of GABA $_{\mathrm{A}}$ ). DHEA and DHEAS have pleiotropic effects, however, and it is possible that multiple other mechanisms of action contribute to their analgesic actions. A better understanding of these actions may inform the direction for future therapeutics. For example, DHEA and DHEAS demonstrate neuroprotective effects in multiple animal models. DHEA and/or DHEAS are protective against oxidative stress [52], and the excitotoxic effects of NMDA, AMPA ( $\alpha$-amino-3-hydroxy-5-methyl-4-isoxazole propionic acid), kainic acid [53-54], and anoxia [55] in rodent models. Additionally, DHEA has neuroprotective effects in autoimmune neurodegenerative processes [5658], brain ischemia [59], and brain trauma [60-62]. DHEA and/or DHEAS also demonstrate anti-inflammatory effects [63-65] and increase neurogenesis [66-68]. Thus, potential analgesic effects of DHEA and/or DHEAS may result, at least in part, from their anti-inflammatory actions. Moreover, DHEA and DHEAS are precursors to other steroids such as testosterone and estradiol, and it is possible that conversion to sex steroid metabolites (i.e., estrogens and androgens) may also play a role in their analgesic actions [32,69-70]. In addition, the timing of DHEA or DHEAS administration may be an important component of the effect of these molecules on pain physiology. For example, DHEAS may have neuroprotective properties in transient forebrain ischemia [71] and brain trauma [72-74] that are biphasic. While DHEA has been shown to protect against brain ischemia, this neuroprotective property may depend upon the timing of DHEA administration. For example, DHEA administered 3 to 48 $\mathrm{h}$ following ischemia is neuroprotective, but administration of this neurosteroid $1 \mathrm{~h}$ before or shortly after ischemia results in increased neuronal death [59]. There thus appear to be multiple complex mechanisms of action that may be contributing to the analgesic actions of DHEAS and DHEA, and it is possible that a combination of effects (rather than a single mechanism) may be involved.

\section{Future Directions}

This exploratory pilot investigation of 403 female Iraq and Afghanistan-era Veterans will require replication in a larger cohort of female participants. In addition, an examination of DHEA and DHEAS levels in male Iraq/ Afghanistan-era Veterans and possible relationships to pain symptoms will be important; considering pronounced sex differences in DHEA and DHEAS levels, the investigation of these molecules in both males and females could contribute to the understanding of sex differences in the neurobiology of pain. Given recent promising neuroimaging findings following DHEA administration [45-46], the use of neuroimaging approaches in the future could also yield new insights into the possible mechanistic contributions of DHEA and DHEAS to the physiology and therapeutics of pain and provide potential biomarker data for the prediction of therapeutic response to neurosteroid interventions. In addition, examining the genetic underpinnings of neurosteroid synthesis and metabolism will be critical.

\section{Limitations}

There are several limitations to this exploratory study in 403 female Iraq/Afghanistan-era Veterans. Because only female Veterans were examined in this pilot study, it 
is not known whether results will also generalize to male Iraq/Afghanistan-era Veterans. In addition, blood draw time varied to some degree within this cohort, although the majority of participants (approximately 90\%) had a blood draw within a $4 \mathrm{~h}$ window (10:30 a.m. to 2:30 p.m.). Although DHEAS demonstrates minimal diurnal variation [75], the diurnal variation pattern of DHEA is more pronounced (and could potentially explain lack of significant findings for DHEA compared with DHEAS). It is also possible, however, that the absence of DHEA findings simply reflects a negative study. In addition, single items were used to assess self-reported pain experienced within the past $7 \mathrm{~d}$ on a scale of 0 (no pain) to 4 (extreme pain) with the SCL-90-R. These questions do not address duration of pain symptoms, however, and it is not known whether participants were reporting acute or chronic pain symptoms. No self-reported pain symptoms were associated with serum DHEA levels, and only self-reported low back pain was inversely associated with serum DHEAS levels (uncorrected for multiple comparisons). However, DHEAS levels were significantly lower among female Veterans reporting moderate to severe low back pain (corrected for multiple comparisons), and thus, the relationship between self-reported pain symptoms and DHEAS levels warrants further investigation. Information with regard to the possible effects of these self-reported pain symptoms on level of function is also not available in this PDMH Study cohort of female Veterans. Associations between neurosteroid levels and self-reported pain symptoms are solely correlational, and causality cannot be assumed. Future studies will be necessary to determine whether altered neurosteroid levels at baseline may predispose individuals to experiencing greater pain symptoms and/or pain may result in altered neurosteroid levels. These results should thus be viewed as very preliminary and will require replication in larger cohorts.

\section{CONCLUSIONS}

DHEAS is inversely associated with self-reported low back pain symptoms in 403 female Iraq/Afghanistan-era Veterans, and female Veterans reporting moderate to extreme pain demonstrate significantly reduced DHEAS levels compared with female Veterans reporting few or no back pain symptoms. These findings provide additional support for the potential analgesic effect of DHEAS and suggest that neurosteroids may have promise as bio- marker candidates and novel therapeutics for pain conditions. Further research with larger Veteran cohorts will be required to replicate the current findings and to determine whether DHEAS levels are also inversely associated with pain symptoms in male Veterans. This exploratory study supports a role for neurosteroids in pain physiology and provides additional rationale for the development of neurosteroid therapeutics for pain analgesia.

\section{ACKNOWLEDGMENTS}

\section{Author Contributions:}

Study concept and design: C. E. Marx, J. C. Naylor, H. R. Wagner, R. M. Hamer.

Acquisition of data: C. E. Marx, L. J. Shampine, J. D. Kilts, MIRECC Workgroup.

Analysis and interpretation of data: C. E. Marx, H. R. Wagner, J. C. Naylor, J. D. Kilts, L. J. Shampine, J. L. Strauss, S. T. Szabo. Drafting of manuscript: J. C. Naylor, C. E. Marx, J. D. Kilts, H. R. Wagner, J. L. Strauss.

Critical revision of manuscript for important intellectual content: J. R. Zanga, C. E. Dunn, S. T. Szabo, MIRECC Workgroup.

Statistical analysis: H. R. Wagner, R. M. Hamer.

Obtained funding: C. E. Marx, J. C. Naylor.

Financial Disclosures: Dr. Marx is an applicant or coapplicant on pending patent applications focusing on the use of neurosteroids and derivatives for central nervous system disorders and for lowering cholesterol (no patents issued, no licensing in place; VA 208 waiver in place).

Funding/Support: This material was based on work supported by a VA Career Development Transition Award (Dr. Marx), VA Merit Review Awards (Dr. Marx), and the VA MIRECC (Dr. Fairbank). Dr. Naylor is funded by a VA Rehabilitation Research and Development Career Development Award (11K2RX000908).

Additional Contributions: The VA MIRECC workgroup includes Jean C. Beckham, PhD; Mira Brancu, PhD; Patrick S. Calhoun, PhD; Eric B. Elbogen, PhD; John A. Fairbank, PhD; Harold S. Kudler, MD; Scott D. Moore, MD, PhD; Kristy A. Straits-Troster; Larry A. Tupler, $\mathrm{PhD}$; Richard D. Weiner, MD, PhD; Antony Fernandez, MD; Robin Hurley, MD; Gregory McCarthy, PhD; Scott D. McDonald, PhD; Katherine H. Taber, PhD; John Mason, PsyD; Marinell Miller-Mumford, PhD; Treven C. Pickett, PsyD; Elizabeth VanVoorhees, PhD; Jennifer J. Runnals, PhD; Jared Rowland, PhD; and Angela Kirby, MA. Institutional Review: The study protocol was approved by the local IRBs at the Durham VA Medical Center, Hampton VA Medical Center, Hunter Holms McGuire VA Medical Center, and W.G. (Bill) Hefner VA Medical Center, and all participants provided written informed consent.

Participant Follow-up: The authors do not plan to inform participants of the publication of this study.

Disclaimer: The views expressed in this article are those of the authors and do not necessarily reflect the position or policy of the VA or U.S. Government. 


\section{REFERENCES}

1. Pain Management Task Force. Washington (DC): Office of the Army Surgeon General; 2010:1-163. Available from: http://www.regenesisbio.com/pdfs/journal/ pain_management task_force_report.pdf

2. Bilmes L. Soldiers returning from Iraq and Afghanistan: The long-term costs of providing veterans medical care and disability benefits. Proceedings of the Allied Social Sciences Association Meetings; 2007 Jan 8; Chicago, IL.

3. Gironda RJ, Clark ME, Ruff RL, Chait S, Craine M, Walker $\mathrm{R}$, Scholten J. Traumatic brain injury, polytrauma, and pain: Challenges and treatment strategies for the polytrauma rehabilitation. Rehabil Psychol. 2009;54(3):247-58.

[PMID:19702423] http://dx.doi.org/10.1037/a0016906

4. Helmer DA, Chandler HK, Quigley KS, Blatt M, Teichman R, Lange G. Chronic widespread pain, mental health, and physical role function in OEF/OIF veterans. Pain Med. 2009;10(7):1174-82. [PMID:19818029] http://dx.doi.org/10.1111/j.1526-4637.2009.00723.x

5. Taylor BC, Hagel EM, Carlson KF, Cifu DX, Cutting A, Bidelspach DE, Sayer NA. Prevalence and costs of cooccurring traumatic brain injury with and without psychiatric disturbance and pain among Afghanistan and Iraq War Veteran V.A. users. Med Care. 2012;50(4):342-46. [PMID:22228249] http://dx.doi.org/10.1097/MLR.0b013e318245a558

6. Riley JL 3rd, Robinson ME, Wise EA, Myers CD, Fillingim RB. Sex differences in the perception of noxious experimental stimuli: A meta-analysis. Pain. 1998;74(2-3): 181-87. [PMID:9520232] http://dx.doi.org/10.1016/S0304-3959(97)00199-1

7. Fillingim RB. Sex, gender, and pain: Women and men really are different. Curr Rev Pain. 2000;4(1):24-30. [PMID:10998712] http://dx.doi.org/10.1007/s11916-000-0006-6

8. Paller CJ, Campbell CM, Edwards RR, Dobs AS. Sexbased differences in pain perception and treatment. Pain Med. 2009;10(2):289-99. [PMID:19207233] http://dx.doi.org/10.1111/j.1526-4637.2008.00558.x

9. Lipton RB, Bigal ME. The epidemiology of migraine. Am J Med. 2005;118(Suppl 1):3S-10S. [PMID:15841882]

10. Lipton RB, Stewart WF. Migraine headaches: Epidemiology and comorbidity. Clin Neurosci. 1998;5(1):2-9. [PMID:9523051]

11. Schwartz BS, Stewart WF, Simon D, Lipton RB. Epidemiology of tension-type headache. JAMA. 1998;279(5):38183. [PMID:9459472] http://dx.doi.org/10.1001/jama.279.5.381

12. LeResche L. Epidemiology of temporomandibular disorders: Implications for the investigation of etiologic factors.
Crit Rev Oral Biol Med. 1997;8(3):291-305.

[PMID:9260045]

http://dx.doi.org/10.1177/10454411970080030401

13. Rauhala K, Oikarinen KS, Järvelin MR, Raustia AM. Facial pain and temporomandibular disorders: An epidemiological study of the Northern Finland 1966 Birth Cohort. Cranio. 2000;18(1):40-46. [PMID:11202814]

14. Stavropoulos F, Hastie BA. Chronic facial pain in the female patient: Treatment updates. Oral Maxillofac Surg Clin North Am. 2007;19(2):245-58, vii. [PMID:18088882] http://dx.doi.org/10.1016/j.coms.2007.01.010

15. Wolfe F, Ross K, Anderson J, Russell IJ, Hebert L. The prevalence and characteristics of fibromyalgia in the general population. Arthritis Rheum. 1995;38(1):19-28.

[PMID:7818567] http://dx.doi.org/10.1002/art.1780380104

16. Ruau D, Liu LY, Clark JD, Angst MS, Butte AJ. Sex differences in reported pain across 11,000 patients captured in electronic medical records. J Pain. 2012;13(3):228-34. [PMID:22245360] http://dx.doi.org/10.1016/j.jpain.2011.11.002

17. Cepeda MS, Carr DB. Women experience more pain and require more morphine than men to achieve a similar degree of analgesia. Anesth Analg. 2003;97(5):1464-68. [PMID:14570666] http://dx.doi.org/10.1213/01.ANE.0000080153.36643.83

18. Crook J, Rideout E, Browne G. The prevalence of pain complaints in a general population. Pain. 1984;18(3):299314. [PMID:6728496] http://dx.doi.org/10.1016/0304-3959(84)90824-8

19. Racine M, Tousignant-Laflamme Y, Kloda LA, Dion D, Dupuis G, Choinière M. A systematic literature review of 10 years of research on sex/gender and pain perceptionPart 2: Do biopsychosocial factors alter pain sensitivity differently in women and men? Pain. 2012;153(3):619-35. [PMID:22236999] http://dx.doi.org/10.1016/j.pain.2011.11.026

20. Kaur S, Stechuchak KM, Coffman CJ, Allen KD, Bastian LA. Gender differences in health care utilization among veterans with chronic pain. J Gen Intern Med. 2007;22(2): 228-33. [PMID:17356991] http://dx.doi.org/10.1007/s11606-006-0048-5

21. Weimer MB, Macey TA, Nicolaidis C, Dobscha SK, Duckart JP, Morasco BJ. Sex differences in the medical care of VA patients with chronic non-cancer pain. Pain Med. 2013;14(12):1839-47. [PMID:23802846]

http://dx.doi.org/10.1111/pme.12177

22. Haskell SG, Brandt CA, Krebs EE, Skanderson M, Kerns RD, Goulet JL. Pain among Veterans of Operations Enduring Freedom and Iraqi Freedom: Do women and men differ? Pain Med. 2009;10(7):1167-73. [PMID:19818028] http://dx.doi.org/10.1111/j.1526-4637.2009.00714.x 
23. Haskell SG, Ning Y, Krebs E, Goulet J, Mattocks K, Kerns R, Brandt C. Prevalence of painful musculoskeletal conditions in female and male veterans in 7 years after return from deployment in Operation Enduring Freedom/Operation Iraqi Freedom. Clin J Pain. 2012;28(2):163-67.

[PMID:21677563] http://dx.doi.org/10.1097/AJP.0b013e318223d951

24. VA Palo Alto Health Care System Women's Health Evaluation Initiative; U.S. Women Veterans Health Strategic Health Care Group. Sourcebook: Women veterans in the Veterans Health Administration. Volume 1. Sociodemographic characteristics and use of VHA care. Washington (DC): Women Veterans Health Strategic Health Care Group, Veterans Health Administration, Department of Veterans Affairs; 2010.

25. Baulieu EE. Neurosteroids: Of the nervous system, by the nervous system, for the nervous system. Recent Prog Horm Res. 1997;52:1-32. [PMID:9238846]

26. Corpéchot C, Robel P, Axelson M, Sjövall J, Baulieu EE. Characterization and measurement of dehydroepiandrosterone sulfate in rat brain. Proc Natl Acad Sci USA. 1981; 78(8):4704-7. [PMID:6458035]

http://dx.doi.org/10.1073/pnas.78.8.4704

27. Paul SM, Purdy RH. Neuroactive steroids. FASEB J. 1992;6(6):2311-22. [PMID:1347506]

28. Aloisi AM, Buonocore M, Merlo L, Galandra C, Sotgiu A, Bacchella L, Ungaretti M, Demartini L, Bonezzi C. Chronic pain therapy and hypothalamic-pituitary-adrenal axis impairment. Psychoneuroendocrinology. 2011;36(7): 1032-39. [PMID:21256679] http://dx.doi.org/10.1016/j.psyneuen.2010.12.017

29. Choe MA, An GJ. [Effect of dehydroepiandrosterone on affected and unaffected hindlimb muscles in rats with neuropathic pain induced by unilateral peripheral nerve injury]. J Korean Acad Nurs. 2009;39(5):632-40. Korean. [PMID:19901493] http://dx.doi.org/10.4040/jkan.2009.39.5.632

30. Freitas RP, Lemos TM, Spyrides MH, Sousa MB. Influence of cortisol and DHEA-S on pain and other symptoms in post menopausal women with fibromyalgia. J Back Musculoskelet Rehabil. 2012;25(4):245-52. [PMID:23220807]

31. Gąsińska E, Bujalska-Zadrożny M, Sar M, MakulskaNowak H. Influence of acute and subchronic oral administration of dehydroepiandrosterone (DHEA) on nociceptive threshold in rats. Pharmacol Rep. 2012;64(4):965-69. [PMID:23087149] http://dx.doi.org/10.1016/S1734-1140(12)70892-7

32. Kibaly C, Meyer L, Patte-Mensah C, Mensah-Nyagan AG. Biochemical and functional evidence for the control of pain mechanisms by dehydroepiandrosterone endogenously synthesized in the spinal cord. FASEB J. 2008;22(1):93-104.
[PMID:17720801]

http://dx.doi.org/10.1096/fj.07-8930com

33. Kilts JD, Tupler LA, Keefe FJ, Payne VM, Hamer RM, Naylor JC, Calnaido RP, Morey RA, Strauss JL, Parke G, Massing MW, Youssef NA, Shampine LJ, Marx CE; Veterans Affairs Mid-Atlantic Mental Illness, Research, Education and Clinical Center Workgroup. Neurosteroids and self-reported pain in veterans who served in the U.S. Military after September 11, 2001. Pain Med. 2010;11(10): 1469-76. [PMID:20735755] http://dx.doi.org/10.1111/j.1526-4637.2010.00927.x

34. Yamamotova A, Kmoch V, Papezova H. Role of dehydroepiandrosterone and cortisol in nociceptive sensitivity to thermal pain in anorexia nervosa and healthy women. Neuroendocrinol Lett. 2012;33(4):401-5. [PMID:22936264]

35. Yoon SY, Roh DH, Seo HS, Kang SY, Han HJ, Beitz AJ, Lee JH. Intrathecal injection of the neurosteroid, DHEAS, produces mechanical allodynia in mice: Involvement of spinal sigma-1 and GABA receptors. Br J Pharmacol. 2009;157(4):666-73. [PMID:19422393] http://dx.doi.org/10.1111/j.1476-5381.2009.00197.x

36. Park-Chung M, Malayev A, Purdy RH, Gibbs TT, Farb DH. Sulfated and unsulfated steroids modulate gammaaminobutyric acid A receptor function through distinct sites. Brain Res. 1999;830(1):72-87. [PMID:10350561] http://dx.doi.org/10.1016/S0006-8993(99)01381-5

37. Bergeron R, de Montigny C, Debonnel G. Potentiation of neuronal NMDA response induced by dehydroepiandrosterone and its suppression by progesterone: Effects mediated via sigma receptors. J Neurosci. 1996;16(3):1193-1202. [PMID:8558248]

38. Finset A, Øverlie I, Holte A. Musculo-skeletal pain, psychological distress, and hormones during the menopausal transition. Psychoneuroendocrinology. 2004;29(1):49-64. [PMID:14575729] http://dx.doi.org/10.1016/S0306-4530(02)00134-8

39. Genazzani AR, Inglese S, Lombardi I, Pieri M, Bernardi F, Genazzani AD, Rovati L, Luisi M. Long-term low-dose dehydroepiandrosterone replacement therapy in aging males with partial androgen deficiency. Aging Male. 2004; 7(2):133-43. [PMID:15672938] http://dx.doi.org/10.1080/13685530412331284669

40. Daniell HW. DHEAS deficiency during consumption of sustained-action prescribed opioids: Evidence for opioidinduced inhibition of adrenal androgen production. J Pain. 2006;7(12):901-7. [PMID:17157776] http://dx.doi.org/10.1016/j.jpain.2006.04.011

41. Genud R, Merenlender A, Gispan-Herman I, Maayan R, Weizman A, Yadid G. DHEA lessens depressive-like behavior via GABA-ergic modulation of the mesolimbic system. Neuropsychopharmacology. 2009;34(3):577-84. 
JRRD, Volume 53, Number 4, 2016

\section{[PMID:18496525]}

http://dx.doi.org/10.1038/npp.2008.46

42. Wong SY, Leung JC, Kwok T, Ohlsson C, Vandenput L, Leung PC, Woo J. Low DHEAS levels are associated with depressive symptoms in elderly Chinese men: Results from a large study. Asian J Androl. 2011;13(6):898-902.

[PMID:21874029]

http://dx.doi.org/10.1038/aja.2011.116

43. Barrett-Connor E, von Mühlen D, Laughlin GA, Kripke A. Endogenous levels of dehydroepiandrosterone sulfate, but not other sex hormones, are associated with depressed mood in older women: The Rancho Bernardo Study. J Am Geriatr Soc. 1999;47(6):685-91. [PMID:10366167] http://dx.doi.org/10.1111/j.1532-5415.1999.tb01590.x

44. Morsink LF, Vogelzangs N, Nicklas BJ, Beekman AT, Satterfield S, Rubin SM, Yaffe K, Simonsick E, Newman AB, Kritchevsky SB, Penninx BW; Health ABC study. Associations between sex steroid hormone levels and depressive symptoms in elderly men and women: Results from the Health ABC study. Psychoneuroendocrinology. 2007;32(810):874-83. [PMID:17651906] http://dx.doi.org/10.1016/j.psyneuen.2007.06.009

45. Sripada RK, Marx CE, King AP, Rajaram N, Garfinkel SN, Abelson JL, Liberzon I. DHEA enhances emotion regulation neurocircuits and modulates memory for emotional stimuli. Neuropsychopharmacology. 2013;38(9):1798-1807. [PMID:23552182] http://dx.doi.org/10.1038/npp.2013.79

46. Sripada RK, Welsh RC, Marx CE, Liberzon I. The neurosteroids allopregnanolone and dehydroepiandrosterone modulate resting-state amygdala connectivity. Hum Brain Mapp. 2014;35(7):3249-61. [PMID:24302681] http://dx.doi.org/10.1002/hbm.22399

47. Strous RD, Maayan R, Lapidus R, Stryjer R, Lustig M, Kotler M, Weizman A. Dehydroepiandrosterone augmentation in the management of negative, depressive, and anxiety symptoms in schizophrenia. Arch Gen Psychiatry. 2003;60(2):133-41. [PMID:12578430]

http://dx.doi.org/10.1001/archpsyc.60.2.133

48. Schmidt PJ, Daly RC, Bloch M, Smith MJ, Danaceau MA, St Clair LS, Murphy JH, Haq N, Rubinow DR. Dehydroepiandrosterone monotherapy in midlife-onset major and minor depression. Arch Gen Psychiatry. 2005;62(2):154-62.

[PMID:15699292]

http://dx.doi.org/10.1001/archpsyc.62.2.154

49. Craft RM, Mogil JS, Aloisi AM. Sex differences in pain and analgesia: The role of gonadal hormones. Eur J Pain. 2004;8(5):397-411. [PMID:15324772] http://dx.doi.org/10.1016/j.ejpain.2004.01.003

50. Derogatis LR. SCL-90-R: Symptom Checklist-90-R: Administration, scoring, \& procedures manual. 3rd ed. Minneapolis (MN): National Computer Systems Inc; 1994.
51. Hochberg Y. A sharper Bonferroni procedure for multiple tests of significance. Biometrika. 1988;75(4):800-802.

http://dx.doi.org/10.1093/biomet/75.4.800

52. Sinha N, Baquer NZ, Sharma D. Anti-lipidperoxidative role of exogenous dehydroepiendrosterone (DHEA) administration in normal ageing rat brain. Indian J Exp Biol. 2005;43(5):420-24. [PMID:15900906]

53. Kimonides VG, Khatibi NH, Svendsen CN, Sofroniew MV, Herbert J. Dehydroepiandrosterone (DHEA) and DHEAsulfate (DHEAS) protect hippocampal neurons against excitatory amino acid-induced neurotoxicity. Proc Natl Acad Sci U S A. 1998;95(4):1852-57. [PMID:9465106]

54. Kurata K, Takebayashi M, Morinobu S, Yamawaki S. Betaestradiol, dehydroepiandrosterone, and dehydroepiandrosterone sulfate protect against N-methyl-D-aspartate-induced neurotoxicity in rat hippocampal neurons by different mechanisms. J Pharmacol Exp Ther. 2004;311(1): 237-45. [PMID:15175425]

http://dx.doi.org/10.1124/jpet.104.067629

55. Marx CE, Jarskog LF, Lauder JM, Gilmore JH, Lieberman JA, Morrow AL. Neurosteroid modulation of embryonic neuronal survival in vitro following anoxia. Brain Res. 2000;871(1):104-12. [PMID:10882789] http://dx.doi.org/10.1016/S0006-8993(00)02452-5

56. Du C, Khalil MW, Sriram S. Administration of dehydroepiandrosterone suppresses experimental allergic encephalomyelitis in SJL/J mice. J Immunol. 2001;167(12):7094-7101. [PMID:11739531] http://dx.doi.org/10.4049/jimmunol.167.12.7094

57. Regelson W, Loria R, Kalimi M. Dehydroepiandrosterone (DHEA) - the "mother steroid." I. Immunologic action. Ann N Y Acad Sci. 1994;719:553-63. [PMID:8010623]

58. Tan XD, Dou YC, Shi CW, Duan RS, Sun RP. Administration of dehydroepiandrosterone ameliorates experimental autoimmune neuritis in Lewis rats. J Neuroimmunol. 2009;207(1-2):39-44. [PMID:19174309] http://dx.doi.org/10.1016/j.jneuroim.2008.11.011

59. Li Z, Cui S, Zhang Z, Zhou R, Ge Y, Sokabe M, Chen L. DHEA-neuroprotection and -neurotoxicity after transient cerebral ischemia in rats. J Cereb Blood Flow Metab. 2009;29(2):287-96. [PMID:18854841] http://dx.doi.org/10.1038/jcbfm.2008.118

60. Fiore C, Inman DM, Hirose S, Noble LJ, Igarashi T, Compagnone NA. Treatment with the neurosteroid dehydroepiandrosterone promotes recovery of motor behavior after moderate contusive spinal cord injury in the mouse. J Neurosci Res. 2004;75(3):391-400. [PMID:14743452] http://dx.doi.org/10.1002/jnr.10821

61. García-Estrada J, Luquín S, Fernández AM, Garcia-Segura LM. Dehydroepiandrosterone, pregnenolone and sex steroids down-regulate reactive astroglia in the male rat brain after a penetrating brain injury. Int J Dev Neurosci. 1999; 
17(2):145-51. [PMID:10221674]

http://dx.doi.org/10.1016/S0736-5748(98)00065-3

62. Hoffman SW, Virmani S, Simkins RM, Stein DG. The delayed administration of dehydroepiandrosterone sulfate improves recovery of function after traumatic brain injury in rats. J Neurotrauma. 2003;20(9):859-70.

[PMID:14577864] http://dx.doi.org/10.1089/089771503322385791

63. Altman R, Motton DD, Kota RS, Rutledge JC. Inhibition of vascular inflammation by dehydroepiandrosterone sulfate in human aortic endothelial cells: Roles of PPARalpha and NF-kappaB. Vascul Pharmacol. 2008;48(2-3):76-84. [PMID:18255343] http://dx.doi.org/10.1016/j.vph.2007.12.002

64. Harding G, Mak YT, Evans B, Cheung J, MacDonald D, Hampson G. The effects of dexamethasone and dehydroepiandrosterone (DHEA) on cytokines and receptor expression in a human osteoblastic cell line: Potential steroidsparing role for DHEA. Cytokine. 2006;36(1-2):57-68. [PMID:17161616] http://dx.doi.org/10.1016/j.cyto.2006.10.012

65. Straub RH, Konecna L, Hrach S, Rothe G, Kreutz M, Schölmerich J, Falk W, Lang B. Serum dehydroepiandrosterone (DHEA) and DHEA sulfate are negatively correlated with serum interleukin-6 (IL-6), and DHEA inhibits IL-6 secretion from mononuclear cells in man in vitro: Possible link between endocrinosenescence and immunosenescence. J Clin Endocrinol Metab. 1998;83(6):2012-17.

[PMID:9626133]

http://dx.doi.org/10.1210/jcem.83.6.4876

66. Brewer GJ, Espinosa J, McIlhaney MP, Pencek TP, Kesslak JP, Cotman C, Viel J, McManus DC. Culture and regeneration of human neurons after brain surgery. J Neurosci Methods. 2001;107(1-2):15-23. [PMID:11389937] http://dx.doi.org/10.1016/S0165-0270(01)00342-9

67. Karishma KK, Herbert J. Dehydroepiandrosterone (DHEA) stimulates neurogenesis in the hippocampus of the rat, promotes survival of newly formed neurons and prevents corticosterone-induced suppression. Eur J Neurosci. 2002;16(3):445-53. [PMID:12193187] http://dx.doi.org/10.1046/j.1460-9568.2002.02099.x

68. Rahmani A, Shoae-Hassani A, Keyhanvar P, Kheradmand D, Darbandi-Azar A. Dehydroepiandrosterone stimulates nerve growth factor and brain derived neurotrophic factor in cortical neurons. Adv Pharmacol Sci. 2013;2013: 506191. [PMID:24381588] http://dx.doi.org/10.1155/2013/506191

69. Edinger KL, Frye CA. Testosterone's analgesic, anxiolytic, and cognitive-enhancing effects may be due in part to actions of its 5alpha-reduced metabolites in the hippocampus. Behav Neurosci. 2004;118(6):1352-64.

[PMID:15598144]

http://dx.doi.org/10.1037/0735-7044.118.6.1352
70. Frye CA, Seliga AM. Testosterone increases analgesia, anxiolysis, and cognitive performance of male rats. Cogn Affect Behav Neurosci. 2001;1(4):371-81.

[PMID:12467088]

http://dx.doi.org/10.3758/CABN.1.4.371

71. Tabuchi K, Oikawa K, Uemaetomari I, Tsuji S, Wada T, Hara A. Glucocorticoids and dehydroepiandrosterone sulfate ameliorate ischemia-induced injury of the cochlea. Hear Res. 2003;180(1-2):51-56. [PMID:12782352] http://dx.doi.org/10.1016/S0378-5955(03)00078-9

72. Juhász-Vedres G, Rózsa E, Rákos G, Dobszay MB, Kis Z, Wölfling J, Toldi J, Párducz A, Farkas T. Dehydroepiandrosterone sulfate is neuroprotective when administered either before or after injury in a focal cortical cold lesion model. Endocrinology. 2006;147(2):683-86.

[PMID:16293666]

http://dx.doi.org/10.1210/en.2005-0693

73. Lür G, Rákos G, Juhász-Vedres G, Farkas T, Kis Z, Toldi J. Effects of dehydroepiandrosterone sulfate on the evoked cortical activity of controls and of brain-injured rats. Cell Mol Neurobiol. 2006;26(7-8):1505-19. [PMID:16758322] http://dx.doi.org/10.1007/s10571-006-9073-5

74. Milman A, Zohar O, Maayan R, Weizman R, Pick CG. DHEAS repeated treatment improves cognitive and behavioral deficits after mild traumatic brain injury. Eur Neuropsychopharmacol. 2008;18(3):181-87. [PMID:17669633] http://dx.doi.org/10.1016/j.euroneuro.2007.05.007

75. Zhao Z-Y, Xie Y, Fu Y-R, Li Y-Y, Bogdan A, Touitou Y. Circadian rhythm characteristics of serum cortisol and dehydroepiandrosterone sulfate in healthy Chinese men aged 30 to 60 years. A cross-sectional study. Steroids. 2003; 68(2):133-38. [PMID:12606003]

http://dx.doi.org/10.1016/S0039-128X(02)00167-8

Submitted for publication November 26, 2014. Accepted in revised form October 21, 2015.

This article and any supplementary material should be cited as follows:

Naylor JC, Kilts JD, Strauss JL, Szabo ST, Dunn CE, Wagner HR, Hamer RM, Shampine LJ, Zanga JR; Department of Veterans Affairs Mid-Atlantic Mental Illness Research, Education, and Clinical Center Workgroup; Marx CE. An exploratory pilot investigation of neurosteroids and selfreported pain in female Iraq/Afghanistan-era Veterans. J Rehabil Res Dev. 2016;53(4):499-510.

http://dx.doi.org/10.1682/JRRD.2014.11.0294

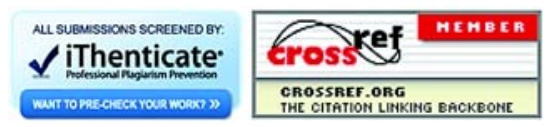


